\title{
Corneal epithelial wound healing
}

\author{
H S Dua, J A P Gomes, A Singh
}

The corneal surface is, without question, the most specialised $123 \mathrm{~mm}^{2 \star}$ of the body's surface. It forms an integral part of the ocular surface with which it shares several anatomical and physiological attributes. Like the rest of the body surface, it is in a state of constant 'healing'. Squamous epithelial cells are continually shed into the tear pool and simultaneously replenished by cells moving centrally from the limbus and anteriorly from the basal layers of the epithelium. This concept was propounded by Thoft ${ }^{1}$ in his $\mathrm{X}, \mathrm{Y}, \mathrm{Z}$ hypothesis and is substantiated by several observations and experiments. $\mathrm{X}$ represents the proliferation of basal epithelial cells, $\mathrm{Y}$ is the proliferation and centripetal migration of the limbal cells, and $\mathrm{Z}$ the epithelial cell loss from the surface. For a state of equilibrium to be maintained $\mathrm{X}+\mathrm{Y}$ must equal $\mathrm{Z}$. It is estimated that the corneal epithelium is constantly renewed every 7 to 10 days. $^{2}$

When this equilibrium is disturbed, as occurs dramatically after an abrasion, the corneal epithelial wound healing response sets in. This is essentially an exaggeration of the normal physiological process involving cellular and subcellular events occurring under the influence of extracellular matrix proteins and growth factors.

\section{Applied anatomy and physiology of the ocular surface epithelium}

\section{CORNEA}

The corneal epithelium is about $50 \mu \mathrm{m}$ thick and made up of five to seven layers of very regularly arranged, nonkeratinised, squamous epithelial cells. ${ }^{36}$ The basal layer of columnar cells is tightly adherent to an underlying uniform $50 \mathrm{~nm}$ thick, basement membrane. The basement membrane is composed largely of type IV collagen, laminin, heparin, and some amounts of fibronectin and fibrin. By electron microscopy it is divisible into an anterior clear lamina lucida which provides hemidesmosomal attachments to basal epithelial cells, and a posterior dark lamina densa. Anchoring fibrils composed of type VII collagen anchor the lamina densa to localised anchoring plaques located in the underlying stroma and Bowman's membrane. ${ }^{6}$ Two or three layers of interdigitating, wing, or polygonal cells make up the intermediate layer followed by two layers of small flattened superficial cells. The superficial cells possess tight junctions, zonulae occludens, that obliterate the intercellular space and afford a permeability barrier to the cornea. The anterior plasma membrane of the most superficial layer of cells shows numerous microvilli and microplicae which facilitate transport of metabolites and tear film adhesion. ${ }^{3-6}$ The cytoskeleton of epithelial cells is made up of tonofibrils, keratins, reticulin, and actin. Actin is present predominantly as an apical network under the anterior plasma membrane and

* Surface area $=2 \pi r \times\left(r-V r^{2}-R^{2}\right)$, where $r$ is the radius of curvature of the cornea (average $7.9 \mathrm{~mm}$ ) and $R$ is the radius of the chord (average 5.75) (half the diameter of the cornea, average 11.5). provides a skeletal framework for microplicae and microvilli. ${ }^{7}$

The basal cells are metabolically more active and have more mitochondria than superficial cells. Corneal epithelial nutrient requirements are derived from three sources: the tear film which provides most of the oxygen, the limbal blood vessels, and the aqueous humour which supplies the bulk of glucose and amino acids. B Adrenergic and muscarinic cholinergic receptors are present on the cell membranes. The function of cholinergic receptors is still unclear but adrenergic receptors are directly related to production of cyclic AMP and initiating biochemical and physiological responses of the cells. ${ }^{4}$

\section{LIMBUS}

The epithelium in this transitional zone is about 10 to 12 layers thick, contains melanocytes, Langerhans cells, and a network of blood vessels. Unlike the conjunctiva, it lacks goblet cells. The limbal stroma with its overlying epithelium is arranged in radial fibrovascular elevations, termed the palisades of Vogt, which alternate with epithelial rete ridges. ${ }^{89}$ These palisades are present all around the cornea but are most defined inferiorly and superiorly. The population density of basal cells is maximal in the palisade region. Electron microscopy reveals a heterogeneity in the basal cell population with cells in varying stages of differentiation. The most undifferentiated cells are small and round with little cytoplasm and morphologically resemble progenitor stem cells of other tissue systems.

\section{CONJUNCTIVA}

The bulbar conjunctiva consists of six to nine layers of epithelial cells. These cells are not as regularly and compactly arranged as in the cornea, are smaller, and show wide intercellular spaces. The basal epithelial cells show comparatively few hemidesmosomal attachments to an underlying discontinuous basement membrane. A characteristic feature of the conjunctival epithelium is the presence of mucin secreting goblet cells which comprise approximately $7 \%$ of the basal cell population. Some epithelial cells may contain melanin granules.

Lymphocytes, melanocytes, and Langerhans cells are interspersed in the suprabasal layers of conjunctival epithelium. The conjunctival stroma is a loose connective tissue layer with lymphatics, blood vessels, and a variable number of lymphocytes, mast cells, plasma cells, and neutrophils. ${ }^{310}$

\section{Corneal epithelial wound healing}

The processes involved in the healing of corneal epithelial wounds can be divided into three distinct components: cell migration, cell proliferation, and cell adhesion. All three components are part of a continuous process but the contribution of each can vary depending on the size and depth of the wound and nature of injury. 


\section{EPITHELIAL CELL MIGRATION}

\section{The latent phase}

For the first 4 to 6 hours following an epithelial defect no appreciable decrease in wound size occurs. The wound may in fact become slightly larger owing to sloughing of necrotic cells and retraction and rounding off of cells at the wound edge. This is referred to as the latent phase. ${ }^{11}$ During this phase intracellular synthesis of structural proteins is increased and actin filaments are polymerised and reorganised from the apical to the basal region of cells. ${ }^{7}$ The basal and squamous cells in the vicinity of the wound show thickening and separation. Experiments on rabbits have revealed that, within 2 hours of wounding, all hemidesmosomal attachments between basal cells and the basement membrane disappear over an area extending $50 \mu \mathrm{m}$ to $70 \mu \mathrm{m}$ from the wound edge and are significantly reduced up to $200 \mu \mathrm{m}$ from the edge. ${ }^{11}$ Tight interdigitations between suprabasal squamous cells also disappear but desmosomal attachments are not completely severed. ${ }^{12}$ Surface microvilli are attenuated or lost. ${ }^{5}$ An accumulation of polymorphonuclear cells, arriving principally via the tear fluid, occurs along the wound edge at about 3 hours after injury and later can be seen over the surface of the wound and also in the stroma. ${ }^{511} 1314$

Desquamation of superficial cells and loss of the columnar appearance of basal cells causes a progressive thinning of the epithelium at the wound edge during the latent phase. ${ }^{114}$ The wound margin is reduced to two to three layers of cells, decreasing to a single layer at the leading edge. These flattened epithelial cells show ruffling and folding of the plasma membrane near their free edges to form narrow finger-like (filopodia) or broader coral-like (lamellipodia) processes, extending onto the wound surface. ${ }^{14-16}$ Changes also occur in the non-cellular constituents of the epithelium. Concentrations of fibronectin, fibrinogen, and fibrin increase on the wound surface in 1 to 8 hours. ${ }^{617}$

\section{The linear healing phase}

The latent phase is followed by a linear healing phase ${ }^{11}$ during which the epithelial cells flatten, spread, and actually move across the defect till it is completely covered. This is an active, energy consuming process independent of cell proliferation which also occurs during the linear healing phase. Migration is associated with increased synthesis of proteins and glycoproteins ${ }^{18}$ with glycogen metabolism serving as the energy source. ${ }^{5}$ Experimental studies have shown a dramatic rise in cell water content which increases cell volume allowing it to cover a larger area. Small defects can be covered by this mechanism alone. ${ }^{19}$ Both basal and suprabasal cells participate in the migration process. ${ }^{72}$ The formation of lamellipodia and filopodia marks the beginning of cell migration. This also corresponds with the re-arrangement of actin filaments within these cells. Gipson and Anderson ${ }^{7}$ have demonstrated a dense network of actin filaments at the leading edges of migrating cells and within the podial extensions. Cell migration can be inhibited by blocking polymerisation of actin, ${ }^{21}$ indicating that actin filaments actively participate in the mechanics of cell motion. Lamellipodial and filopodial activity continues at the leading edge until wound closure. Even though several layers of cells participate in migration, a large portion of the defect is initially covered by a single layer of cells. When this occurs, polymorphonuclear cells disappear and normal thickness of epithelium is restored by proliferation and upward movement of cells from the basal layer. ${ }^{2}$

Several studies have indicated that migration of cells occurs in a centripetal manner from the limbus towards the centre of the cornea, not only in wound healing but also during normal replicative epithelial turnover. Experimental evidence for this was provided by observations on migration of goblet cells and limbal pigment onto clear cornea. ${ }^{22}$ This was corroborated by observations on the movement of epithelial microcysts on donor cornea and replacement of sex chromatin of donor cornea by that of host cornea following corneal grafting. ${ }^{24}{ }^{25}$ More direct evidence was provided by demonstrating the centripetal migration of limbal cells marked by India ink. ${ }^{26}$ Buck $^{27}$ has reported the observation that hemidesmosomes of peripheral cells of normal and healing mouse corneas are arranged in radial rows and interpreted this orientation to represent centripetal migration of epithelial cells. Observations on the healing of large central corneal abrasions in humans have also shown centripetal migration of three or more sheets of epithelium with convex leading edges. These arise from the remaining intact peripheral epithelium and continue to extend centrally until they meet along ' $\mathrm{Y}$ shaped contact lines' to close the defect. ${ }^{28}$ The rate of migration has been estimated to be $17 \mu \mathrm{m}$ a day in the mouse model $^{27}$ and $64 \mu \mathrm{m}$ per hour in the rabbit. ${ }^{11}$ Animal studies that have established centripetal migration of cells as the norm, were conducted on central epithelial defects with an intact limbus or on normal corneas. Dua and Forrester ${ }^{29}$ studied human corneal epithelial defects with limbal involvement and clearly demonstrated that a preferential circumferential migration of a population of cells occurs along the limbus, from both ends of the limbal defect. This circumferential migration continues until the advancing ends meet to reestablish epithelial cover for the limbus. They also observed that complete epithelial cover for the corneal surface was not established until limbal re-epithelialisation was first completed (Fig 1). They postulated that the circumferentially migrating population of cells probably represented in part, the healing response of limbal stem cells (see below).

It is generally accepted that epithelial cells migrate en masse as a continuous coherent sheet, with most cells retaining their relative positions to each other, much like the movement of a 'herd of cattle'. ${ }^{2326}$ Although this is largely true, individual cells, or small groups or columns of cells within such sheets, may migrate independently to form small or large swirls or whorls on the surface of the healing cornea. These whorls are best visualised by fluorescein staining and,
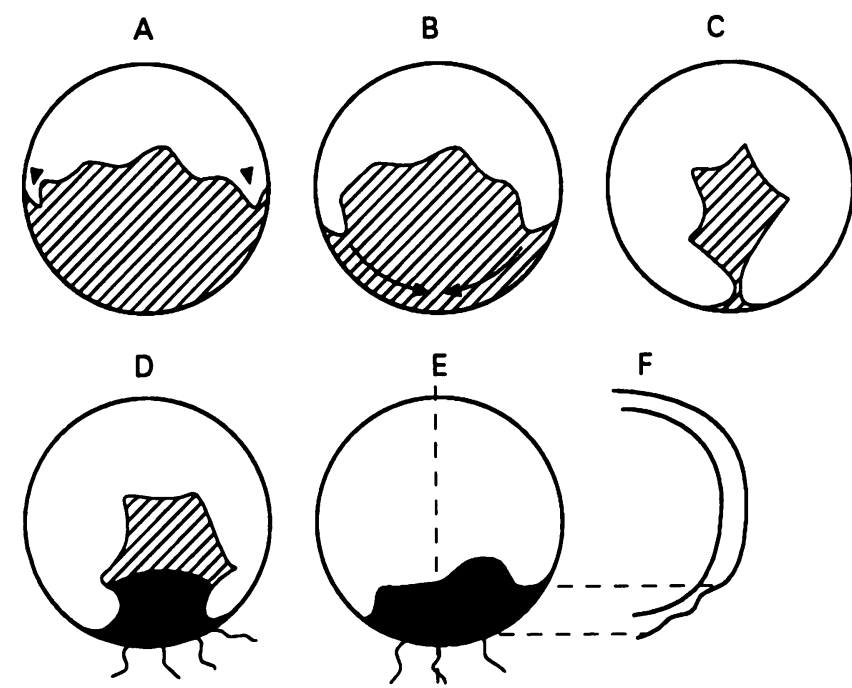

Figure 1 Diagrammatic representation of the healing of an ocular surface defect involving the limbus. (A) Arrowheads indicate the formation of tongue-shaped epithelial sheets, from the remaining intact epithelium, at either end of the limbal defect (hatched area represents fluorescein staining). $(B)$ Arrows indicate the circumferential migration of tongue-shaped sheets along the limbus. (C) Limbal cover is always re-established before the central defect heals. (D) Conjunctival epithelium (solid black) may extend across the limbus to cover the cornea and inhibit further migration of the limbal epithelial sheets. ( $E$ and $F$ ) Area covered by limbal epithelium is sharply demarcated from normal corneal epithelium, is thin, irregular, and attracts new blood vessels. 
when small, are mainly distributed around the 'contact lines' of migrating sheets, ${ }^{28}$ reminiscent of 'iron filings arranged in the magnetic field of a bar magnet'. Large whorls, as seen in 'hurricane keratopathy' of grafted corneas and chronic epitheliopathies, represent similar migration of cells from the periphery to the centre in a vortex pattern..$^{30-32}$ These whorls of 'hurricane keratopathy' resemble those seen in vortex keratopathy due to the deposition of iron, drugs, glycogen, or lipids, ${ }^{33}$ but unlike the latter, are highlighted by fluorescein staining. Mackman et $a l^{30}$ concluded that 'hurricane keratopathy' was a side effect of topical steroid medication. However, Dua et al ${ }^{32}$ suggested that the vortex pattern represents the migratory path of cells during normal epithelial turnover but is clinically not visible as it occurs at a very slow rate and migrating cells cannot be distinguished from surrounding non-migrating cells. When the rate of epithelial migration is increased, as occurs after an epithelial defect, or when migrating cells become visible by the intracellular deposition of substances, the pattern becomes clinically apparent. In the former situation, rapidly migrating cells do not form tight intercellular junctions and are outlined by fluorescein stain, either singly or in small groups or columns. Dua et $a l^{32}$ observed that these whorls were almost always 'clockwise' and postulated that this unique pattern is caused by migrating cells responding to electromagnetic fields generated by the electrical potential of the eye. We have since followed 25 eyes with 'hurricane keratopathy' occurring in corneal grafts and in keratoconus patients wearing rigid contact lenses. In approximately $10 \%$ of these patients the whorl has been 'anticlockwise'. We are also studying the effect of magnetic fields on cultured corneal epithelial cells and preliminary results indicate a dramatic effect on cell migration (unpublished observations).

\section{EPITHELIAL CELL PROLIFERATION}

Although migration is independent of cell proliferation, the two processes complement each other during reepithelialisation. Cell proliferation helps restore cell numbers and cell mass. Following epithelial wounding there is a pause in the natural process of exfoliation and cells near the wound cease to divide for up to 1 day while those at some distance from the wound undergo an increased rate of cell division..$^{120}$ A wave of mitosis moves from the periphery towards the wound and continues until the wound has healed and normal thickness of epithelium restored.

Basal epithelial cells are the chief participants in the proliferative process. $^{234}$ Cumulative evidence has clearly established the limbal basal epithelium as the repository of stem cells for corneal epithelial cells. Stem cells are progenitor cells that are ultimately responsible for cell replacement and tissue regeneration. They are present in all self-renewing tissues, have a long life with a great potential for cell division, are normally slow cycling but can be preferentially stimulated by wounding. ${ }^{35-37}$ Stem cell mitosis serves two purposes; firstly, the renewal of the stem cell population itself and, secondly, the production of more rapidly dividing transient amplifying cells (TAC). TAC divide and differentiate into post mitotic cells (PMC) and eventually into terminally differentiated cells (TDC) which reflect the functional aspects of the tissue concerned. ${ }^{36}$ Schermer et $a l^{38}$ suggested that corneal basal cells represent TAC and suprabasal cells correspond to PMC and TDC.

Evidence for the existence and limbal location of corneal stem cells has come from various sources: $\left[{ }^{3} \mathrm{H}\right]$ thymidine labelling shows that cell mitosis is highest at the corneal periphery/limbus. ${ }^{24}{ }^{35}$ Histological features of regenerated limbal epithelium resemble corneal and not conjunctival epithelium. ${ }^{39}$ A large corneal epithelial wound, where the wound edge is closer to the limbus, heals at a faster rate than a small wound..$^{40}$ On repeated denudation of the central corneal epithelium, the second wound heals at a faster rate than the first indicating that the corneal surface was repopulated by rapidly dividing younger cells from the periphery. ${ }^{41}$ In vitro tissue culture studies have also shown that limbal/peripheral bovine and human epithelial cells grow at a faster rate than central epithelial cells. ${ }^{42-44}$ Several studies ${ }^{295-47}$ have demonstrated that delayed or abnormal corneal epithelial wound healing occurs with limbal epithelial deficiency and, conversely, chronic corneal epithelial healing disorders can be managed successfully by limbal autograft transplantation. ${ }^{3648}$ Development of monoclonal antibodies against a $64 \mathrm{~K}$ keratin $^{38}$ and a $50 \mathrm{~K}$ protein ${ }^{49}$ have enabled the identification of a unique population of basal cells that may represent stem cells, at the limbus..$^{38950}$ Lastly, the centripetal migration of cells itself points towards the limbus as the source of cell generation and central drive. ${ }^{22-28}$

Not all basal cells of the limbus are stem cells. It is estimated that approximately $30 \%$ of mouse limbal basal cells might represent stem cells..$^{36}$ The exact location of these cells is uncertain. Davanger and Evensen ${ }^{\text {s1 }}$ suggested and provided preliminary evidence to indicate that stem cells reside in the interpalisade (of Vogt) rete ridges. Further evidence in support of this was provided by Goldberg and Bron ${ }^{8}$ and Townsend. ${ }^{9}$ We have observed epithelial healing in several patients with corneal grafts and erosions. Fluorescein staining has often revealed alternating columns of stained and unstained cells extending from the limbus towards the corneal centre. These streams of cells tended to be more or less radial when associated with peripheral superficial vascularisation (Fig $2 \mathrm{~A}$ ) or curved and wedge-like in appearance with the broad end towards the limbus or towards the graft host junction and the narrow tapering end curving onto the corneal surface (Fig 2B). When limbal palisades were visible, the cell columns appeared to correspond to interpalisade rete ridges (Fig 2C). A similar streaming of cells onto the grafted cornea was also noted in relation to broken sutures (Fig 2D). These observations lend support to the belief that stem cell activity does not occur contiguously along the limbus but rather in an interrupted manner presumably corresponding to repositories of stem cells in the rete ridges that alternate with palisades which may not hold a similar mass of stem cells.

\section{EPITHELIAL CELL ADHESION}

Corneal epithelial wound healing is not complete until the newly regenerated epithelium has anchored itself firmly to underlying connective tissue. Permanent anchoring units are not formed until the wound defect is completely covered. However, transient attachments are regularly formed and released during the process of cell migration.

Soon after wounding, extracellular matrix proteins like fibronectin, fibrinogen/fibrin, laminin, and tenascin ${ }^{61752}$ appear on the denuded surface. Migrating cells develop focal cell to substrate macromolecular contacts known as adhesion plaques. These are highly specialised membrane cytoskeletal complexes involving intracellular stress fibres, the plasma membrane, and extracellular substrate. In the absence of hemidesmosomes, intracellular actin can mediate such attachments via several cell surface adhesion molecules like vinculin, talin, $\alpha$ actin, fimbrin, and the family of very late activation (VLA) integrins. ${ }^{5354}$ These molecules act as receptors for fibronectin, laminin, and other components of basement membrane.

Focal contacts are first established by lamellipodia and filopodia. These provide anchorage while intracellular contractile mechanisms draw the trailing cells forward. Fibrin and fibronectin stimulate epithelial cells to release plasminogen activator. This in turn converts plasminogen to 
plasmin which lyses cell to substrate adhesions allowing the cells to advance and form new adhesions. This cycle is repeated until migration ceases at wound closure. ${ }^{6}$ These adhesions are relatively weak and regenerating epithelium can be easily peeled off as a sheet. ${ }^{55}$ The rapidity with which permanent hemidesmosomal attachments form depends on whether or not the basement membrane remained intact at the time of wounding. In rabbit eyes, epithelial cells were shown to migrate rapidly and develop strong permanent adhesions within a week, when the basement membrane was left intact. On the other hand, after superficial keratectomy wounds, normal adhesion was not established until 6 weeks. ${ }^{5 s}$ In the latter situation, advancing cells secrete new basement membrane before hemidesmosomes and anchoring fibrils can develop. In ultrastructural studies on monkeys, Hirst et al ${ }^{56}$ showed that corneal epithelial defects caused by scraping, iodine, or cocaine healed normally with the rapid formation of tight adhesions. However, alkali induced defects showed a marked delay in adhesion even in areas where basement membrane had been regenerated. This was attributed to the accumulation of keratocytes, cellular and amorphous debris, and the presence of subepithelial polymorphonuclear leucocytes which prevent anchoring of basement membrane to its collagenous substrate. Hemidesmosome formation corresponds to sites of anchoring fibril attachment to the basement membrane and does not occur in the absence of anchoring fibrils. ${ }^{57}$

The conjunctiva in corneal epithelial wound healing That corneal defects could heal from the conjunctival epithelium has been known for a long time. ${ }^{58}$ Corneal epithelial wounds are known to stimulate a proliferative response in the perilimbal conjunctiva, ${ }^{4059}$ but under normal circumstances the limbal epithelium acts as a barrier and is able to exert an inhibitory growth pressure preventing migration of con-
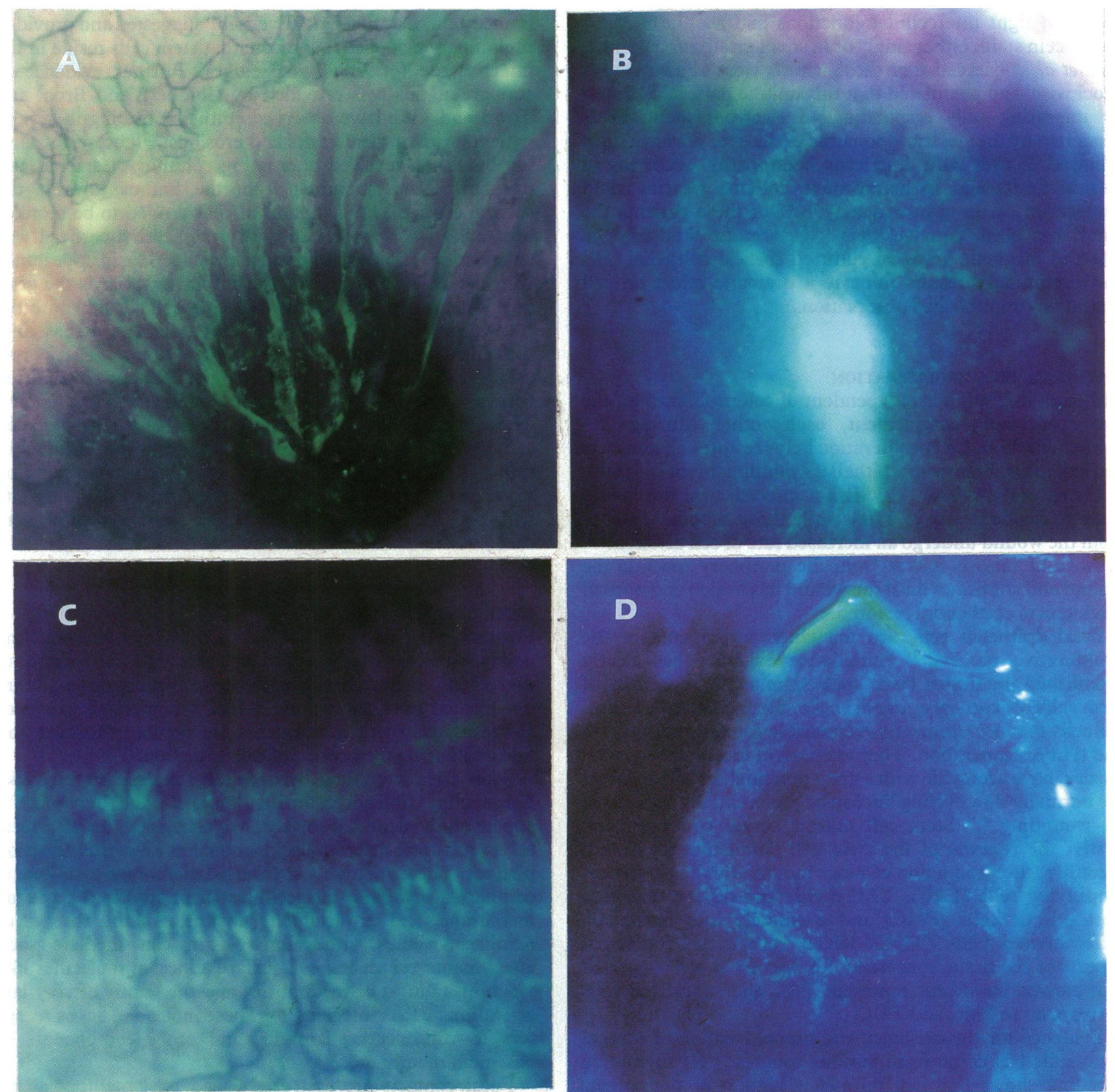

Figure 2 (A) Right eye of a 70-year-old man with rosacea. Note peripheral vascularisation and alternating radial columns of cells migrating from the limbus onto corneal surface. (B) Recurrent erosion in a corneal graft. Wedge-shaped streams of migrating cells with the broad ends at the graft-host junction and the narrow ends curving towards the margin of erosion. There was no peripheral vascularisation. (C) Early migration of alternating columns of cells that correspond to the arrangement of the inferior palisades of Vogt. (D) Streaming of cells in a column from the graft-host junction, in relation to a broken suture. (All photographs with fluorescein stain and cobalt blue filter.) 
junctival epithelial cells onto the cornea. ${ }^{36}$ However, when the epithelial defect involves the limbus, this barrier is lifted and conjunctival migration onto the cornea occurs. This is associated with the appearance of goblet cells and, often, new blood vessels. ${ }^{60}$ Conjunctival epithelium covering the cornea undergoes a slow transformation to assume characteristics resembling corneal epithelium, a process referred to as conjunctival transdifferentiation. Shapiro et $a l^{b_{1}}$ studied this process in rabbits and divided it into five stages depending on the presence and density of goblet cells and the degree of stratification of the conjunctival epithelium. This process has been extensively studied in experimental animals with the following conclusions: goblet cells do not migrate onto the cornea but develop de novo from non-goblet epithelial cells. Loss of goblet cells during transdifferentiation occurs by desquamation and in situ cell death. ${ }^{62}$ Vascularisation of regenerated epithelium is associated with poor transdifferentiation and persistence of goblet cells. ${ }^{63}$ Conversely, transdifferentiation in vascularised corneas can be initiated by photothrombotic occlusion of the new vessels. ${ }^{64}$ Vitamin $A$ is considered to be one of the humoral factors influencing transdifferentiation. Topical vitamin A instillation inhibits the process even in non-vascularised corneas ${ }^{65}$ and conversely transdifferentiation can be induced in vascularised corneas by systemic vitamin A deficiency. ${ }^{66}$ It is hypothesised that normal avascular cornea has a relative vitamin A deficiency which induces squamous metaplasia in conjunctival epithelium with loss of goblet cells. This is reversed by vascularisation which brings with it an excess of vitamin A to induce mucous metaplasia..$^{6466}$

The consensus from most animal studies is that, although complete morphological transdifferentiation is possible, biochemically and functionally it is far from satisfactory. ${ }^{3667-69}$ Conjunctival transdifferentiation in animal models can therefore, at best, be described as squamous metaplasia with loss of goblet cells. Moreover, it has also been suggested that, in many of the above studies, conjunctival transdifferentiation could have occurred owing to incomplete removal of limbal basal epithelium, ${ }^{70}$ with the result that regenerated epithelium demonstrated both corneal and conjunctival features without one are actually changing to the other.

Dua and Forrester ${ }^{29}$ studied the healing of large ocular surface epithelial wounds that involved the cornea, limbus, and conjunctiva in humans. In some patients, as illustrated in Figure 1D-F, they noted a centripetally migrating sheet of conjunctival epithelium that reached and migrated across the limbus, preventing the circumferentially migrating limbal sheets from meeting each other. As a result varying areas of the cornea were covered by conjunctival epithelium. The epithelium in these areas was invariably thinner than adjoining normal corneal epithelium, showed a stippled stain with fluorescein, attracted new vessels, and was prone to recurrent erosions. Since publication of that report, we have studied a similar healing response in patients with corneal grafts and following large abrasions. In all these patients, even several months on, the corneal surface covered by conjunctival cells remained relatively thin and irregular without clinically evident transdifferentiation. The difference in thickness sharply demarcates the area of 'conjunctivalisation' from the adjacent healthy corneal epithelium and is rendered more obvious by the pooling of fluorescein dye (Fig $3 \mathrm{~A}$ and $\mathrm{B}$ ). What is more interesting is that tiny buds of corneal epithelium can be seen protruding into the conjunctival epithelium all along the contact line between the two epithelial phenotypes (Fig 3A and B) (see also Fig 2 in Dua and Forrester ${ }^{29}$ ). These buds are always seen arising from the corneal epithelium and give the impression that normal corneal epithelium is attempting to replace the conjunctival epithelium, gradually nudging it outward, towards the limbus. 'Replacement' of conjunctival epithelium by normal corneal epithelium may therefore be yet another factor contributing to conjunctival transdifferentiation. On the basis of these observations we recommend that, in corneal epithelial defects with partial limbal involvement, conjunctival epithelium should be prevented from crossing the limbus until the circumferentially migrating sheets of limbal epithelium have met each other and the limbal barrier is reestablished. ${ }^{7}$ This can be achieved by mechanically scraping the advancing conjunctival epithelial sheet, and may have to be repeated two or three times because the conjunctival epithelium migrates rapidly compared with the limbal sheets. Such an approach would ensure corneal epithelial cover for the cornea and conjunctival epithelial cover for the conjunctiva. We have in fact successfully performed this pro-
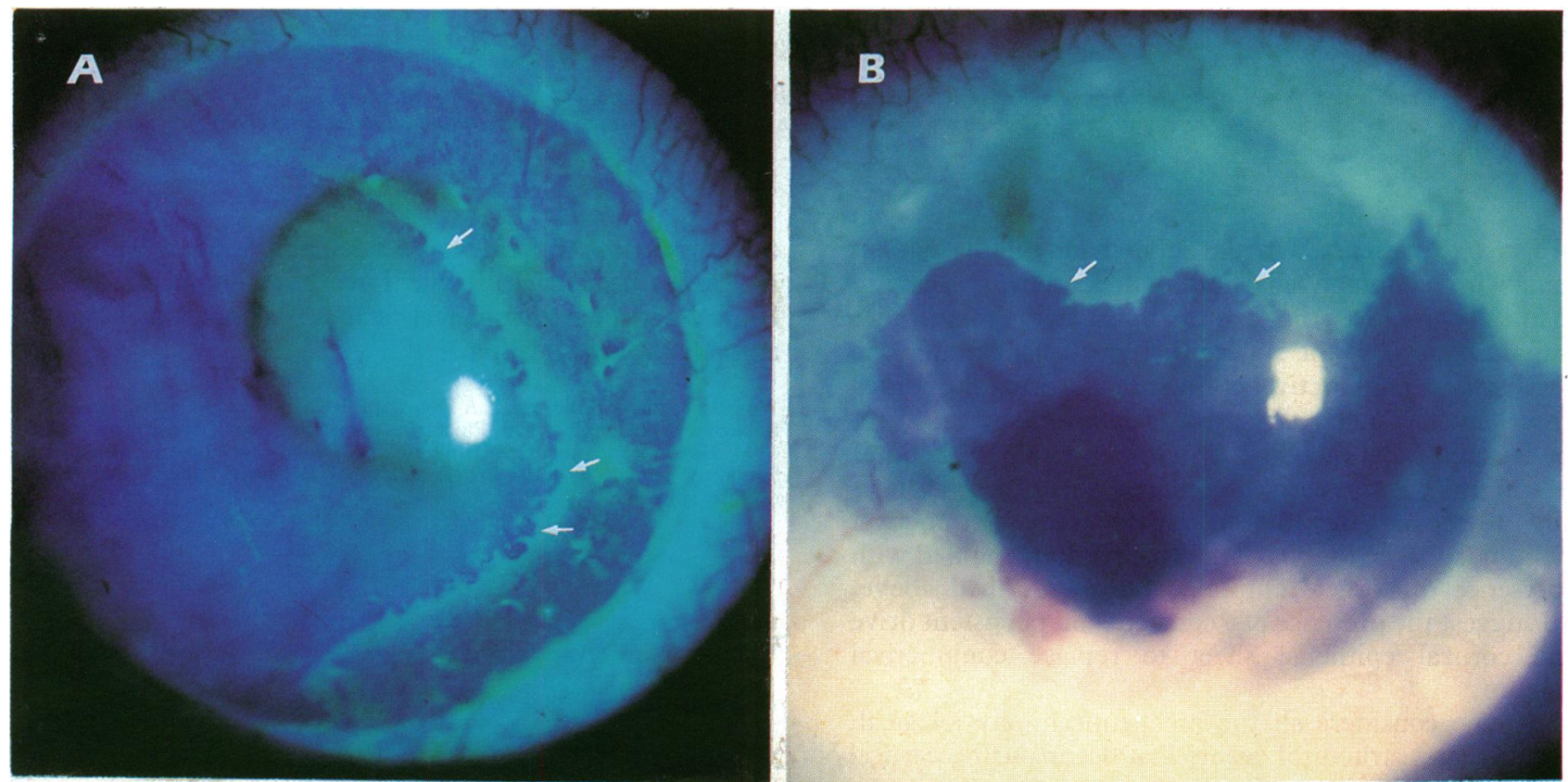

Figure 3 (A and B) Superficial chemical burns of the ocular surface with 'conjunctivalisation' of cornea persisting for 2 and 5 years after injury. The corneal epithelium shows tiny 'buds' (arrows) along the line of contact with conjunctival epithelium. The area covered with conjunctival epithelium is thin and irregular and shows pooling of fluorescein dye where it meets thicker corneal epithelium. 

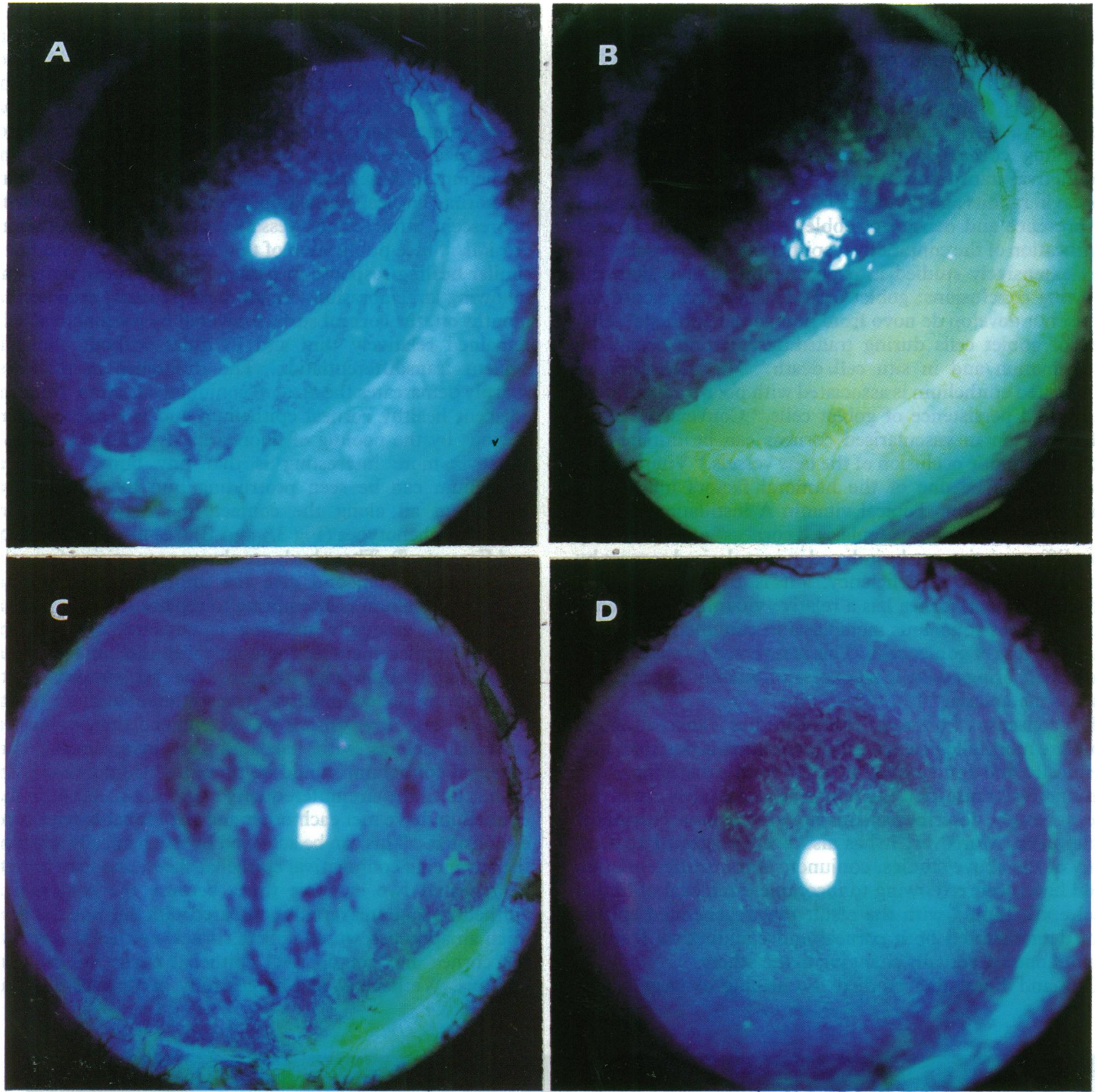

Figure 4 (A) Conjunctivalisation of inferotemporal aspect of left cornea with pooling of fluorescein dye and stippled staining. (B) After conjunctival epithelium was removed with a cotton tip applicator. (C) The same cormea as seen 24 hours later, and (D) 1 week later. The defect is completely covered with corneal epithelium.

cedure in two patients. On the other hand, if the patient presents with 'conjunctivalisation' of the cornea, it is easy to mechanically remove the conjunctival epithelium under topical anaesthesia at the slit-lamp. Figure 4 illustrates one such case where conjunctival epithelium covering the cornea was mechanically removed and was followed by rapid reepithelialisation of the cornea with corneal epithelium. Interestingly, it is the corneal epithelial sheet that advances rapidly to cover the defect rather than conjunctival epithelium from the limbus. This observation, coupled with the presence of corneal epithelial buds described above, would suggest the presence of a constant and persistent drive in the corneal epithelial sheet to replace conjunctival epithelium.

When one considers all the biochemical, physiological, anatomical, and structural events that occur during corneal epithelial wound healing, it is not surprising that the process can be influenced adversely, or in some instances favourably, by a whole host of factors. These factors can be broadly categorised into those that affect cell migration, cell division, and cell adhesion. In Table 1 we have enumerated some clinical and pharmacological factors that can affect corneal epithelial wound healing.

We wish to thank Professors L A Donoso, P R Laibson, E J Cohen, and Dr C J We wish to thank Professors L A Donoso, P R Laibson, E J Cohen, and Dr C J Rapuano, Wills Eye Hospital, Philadelphia, and Professor J V Forrester and Dr C H Hutchinson, Aberdeen University, Scotland, for use of patient data.
Supported in part by the Lions Eye Bank of Delaware Valley, Gene Polgar, Supported in part
executive director.

Wills Eye Hospital, POMES A SINGH

Philadelphia, USA

Department of Ophthalmology,

University Hospital,

Queen's Medical Centre,

Nottingham, UK

Santa Casa Medical School, Sao Paulo, Brazil 
Table 1 Clinical and pharmacological factors affecting corneal epithelial wound healing

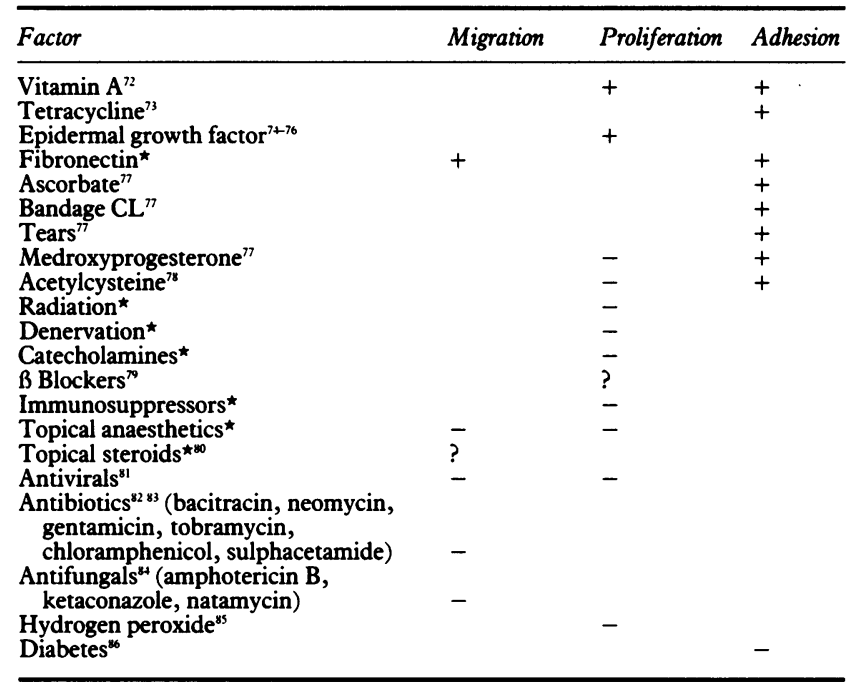

$+=$ Favourable effect; $-=$ unfavourable effect; $?=$ controversial

${ }^{\star}$ See Townsend ${ }^{9}$

1 Thoft RA, Friend J. The X, Y, Z hypothesis of corneal epithelial maintenance. Invest Ophthalmol Vis Sci 1983; 24: 1442-3.

2 Hanna C, O'Brien JE. Cell production and migration in the epithelial layer of the cornea. Arch Ophthalmol 1960; 64: 536-9.

3 Kenyon KR. Anatomy and pathology of the ocular surface. In: Thoft RA, Friend J, eds. International ophthalmology clinics. Vol 19. The ocular surface. Boston: Little, Brown, 1979: 3-36.

4 Friend J. Physiology of the cornea. In: Smolin G, Thoft RA, eds. The cornea, scientific foundations and clinical practice. 2nd ed. Boston: Little, Brown, 1987: 16.

5 Maudgal PC, Missotten L, eds. Monographs in ophthalmology 1. Superficial keratitis. The Hague: Dr W Junk Publishers, 1980.

6 Arffa RC. Diseases of the cornea. In: Grayson's diseases of the cornea. 3rd ed.

7 Gipson IK, Anderson RA. Actin filaments in normal and migrating corneal Gipson IK, Anderson RA. Actin filaments in normal and
epithelial cells. Invest Ophthalmol Vis $S c i$ 1977; 16: 161-6.

8 Goldberg MF, Bron AJ. Limbal palisades of Vogt. Trans Am Ophthalmol Soc 1982; 80: 155-71.

9 Townsend WM. The limbal palisades of Vogt. Trans Am Ophthalmol Soc 1991; 89: 721-56.

10 Friend J, Kenyon KR. Physiology of the conjunctiva. In: Smolin G, Thoft RA, eds. The cormea, scientific foundations and clinical practice. 2nd ed. Boston: Little, Brown, 1987: 52 .

11 Crosson CE, Klyce SD, Beuerman RW. Epithelial wound closure in the rabbi cornea: a biphasic process. Invest Ophthalmol Vis Sci 1986; 27: 464-73.

12 Kuwabara T, Perkins DG, Cogan DG. Sliding of the epithelium in experimental corneal wounds. Invest Ophthalmol 1976; 15: 4-14.

13 Robb RM, Kuwabara T. Corneal wound healing, I. The movement of polymorphonuclear leukocytes into corneal wounds. Arch Ophthalmol 1962; 68: $636-42$

14 Pfister RR. The healing of corneal epithelial abrasions in the rabbit: a scanning electron microscope study. Invest Ophthalmol 1975; 14: 648-61.

15 Brewitt $\mathrm{H}$. Sliding of epithelium in experimental corneal wounds: a scanning electron microscope study. Acta Ophthalmol 1979; 57: 945-58.

16 Haik BC, Zimny ML. Scanning electron microscopy of corneal wound healing in the rabbit. Invest Ophthalmol Vis Sci 1977; 16: 787-96.

17 Fujikawa LS, Foster CS, Harrist TJ, Lanigan JM, Colvin RB. Fibronectin in healing rabbit corneal wounds. Lab Invest 1981; 45: 120-9.

18 Gipson IK, Kiorpes TC. Epithelial sheet movement: protein and glycoprotein synthesis. Dev Biol 1982; 92: 259-62.

19 Cintron C, Kublin CL, Covington H. Quantitative studies of corneal epithelial wound healing in rabbits. Curr Eye Res 1981; 1: 507-16.

20 Hanna C. Proliferation and migration of epithelial cells during corneal wound repair in the rabbit and the rat. Am $\mathcal{F}$ Ophthalmol 1966; 61: 55-62.

21 Soong HK, Cintron C. Disparate effects of calmodulin inhibitors on corneal epithelial migration in rabbit and rat. Ophthalmic Res 1985; 17: 27-33.

$22 \mathrm{Mann} I$. A study of epithelial regeneration in the living eye. Br $\mathcal{F}$ Ophthalmol

1944; 28: $26-40$.
23 Buschke WH. Morphologic changes in cells of corneal epithelium in wound healing. Arch Ophthalmol 1949; 41: 306-16.

24 Kinoshita S, Friend J, Thoft RA. Sex chromatin of donor corneal epithelium in rabbits. Invest Ophthalmol Vis Sci 1981; 21: 434-41.

25 Kaye DB. Epithelial response in penetrating keratoplasty. Am $\mathcal{F}$ Ophthalmol 1980; 89: 381-7.

26 Buck RC. Cell migration in repair of mouse corneal epithelium. Invest Ophthalmol Vis Sci 1979; 18: 767-84

27 Buck RC. Measurement of centripetal migration of normal corneal epithelial cells in the mouse. Invest Ophthalmol Vis Sci 1985; 26: 1296-9.

28 Dua HS, Forrester JV. Clinical patterns of corneal epithelial wound healing. Am f Ophthalmol 1987; 104: 481-9.

29 Dua HS, Forrester JV. The corneoscleral limbus in human corneal epithelial wound healing. Am $\mathcal{F}$ Ophthalmol 1990; 110: 646-56.

30 Mackman GS, Polack FM, Sydrys L. Hurricane keratitis in penetrating keratoplasty. Cornea 1983; 2: 31-4.

31 Lemp MA, Mathers WD. Corneal epithelial cell movement in humans. Eye 1989; 3: 438-45.

32 Dua HS, Watson NJ, Mathur RM, Forrester JV. Corneal epithelial cell migration in humans: hurricane and blizzard keratopathy. Eye 1993; 7: 53-8.
33 Bron AJ. Vortex patterns of the corneal epithelium. Trans Ophthalmol Soc UK 1973; 93: 455-72.

34 Friedenwald JS, Buschke W. Some factors concerned in the mitotic and wound-healing activities of the corneal epithelium. Trans Am Ophthalmol Soc 1944 ; 42: 371-83.

35 Cotsarelis G, Cheng S-Z, Dong G, Sun T-T, Lavker RM. Existence of slowcycling limbal epithelial basal cells that can be preferentially stimulated to proliferate: implications on epithelial stem cells. Cell 1989; 57: 201-9.

36 Tseng SCG. Concept and application of limbal stem cells. Eye 1989; 3: 141-57.

37 Lavker RM, Dong G, Cotsarelis G, Sun T-T. Limbal basal epithelial cells display charactęristics consistent with stem cells from various stratifying epithelia. Invest Ophthalmol Vis Sci (suppl) 1988; 29: 191.

38 Schermer A, Galvin S, Sun T-T. Differentiation-related expression of a major $64 \mathrm{~K}$ corneal keratin in vivo and in culture suggests limbal location of corneal epithelial stem cells. F Cell Biol 1986; 103: 49-62.

39 Kinoshita S, Kiorpes TC, Friend J, Thoft RA. Limbal epithelium in ocular surface wound healing. Invest Ophthalmol Vis Sci 1982; 23: 73-80.

40 Matsuda M, Ubels JL, Edelhauser HF. A larger corneal epithelial wound closes at a faster rate. Invest Ophthalmol Vis Sci 1985; 26: 897-900.

41 Srinivasan BD, Eakins KE. The re-epithelialization of rabbit cornea following single and multiple denudation. Exp Eye Res 1979; 29: 595-600.

42 Eggli P, Boulton M, Marshall J. Growth characteristics of central and peripheral bovine corneal epithelial cells in vitro. Invest Ophthalmol Vis Sci (suppl) 1988; 29: 191.

43 Ebato B, Friend J, Thoft RA. Comparison of central and peripheral human corneal epithelium in tissue culture. Invest Ophthalmol Vis $S c i$ 1987; 28: $1450-6$

44 Ebato B, Friend J, Thoft RA. Comparison of limbal and peripheral human corneal epithelium in tissue culture. Invest Ophthalmol Vis Sci 1988; 29: 1533-7.

45 Huang AJW, Tseng SCG. Corneal epithelial wound healing in the absence of limbal epithelium. Invest Ophthalmol Vis Sci 1991; 32: 96-105.

46 Singh G, Foster CS. Influence of damage to limbal epithelial cells on the morphology of central corneal epithelium and its wound healing. Invest Ophthalmol Vis Sci (suppl) 1988; 29: 190.

47 Chen JJY, Tseng SCG. Abnormal corneal epithelial wound healing in partial thickness removal of limbal epithelium. Invest Ophthalmol Vis Sci 1991; 32: 2219-33.

48 Kenyon KR, Tseng SCG. Limbal autograft transplantation for ocular surface disorders. Ophthalmology 1989; 96: 709-23.

49 Zieske JD, Bukusoglu G, Yankauckas MA. Characterization of a potential marker of corneal epithelial stem cells. Invest Ophthalmol Vis Sci 1992; 33: 143-52.

50 Chung E-H, Bukusoglu G, Zieske JD. Localization of corneal epithelial stem cells in the developing rat. Invest Ophthalmol Vis Sci 1992; 33: 2199-206.

51 Davanger M, Evensen A. Role of the pericorneal papillary structure in renewal of corneal epithelium. Nature 1971; 229: 560-1.

52 Tervo T, van Setten G-B, Beuerman RW, Tervo K, Virtanen I, Tarkkanen A. Appearance of immunohistochemically detectable cellular fibronectin and tenascin in the experimental rabbit keratectomy wound. Invest Ophthalmol Vis $S c i$ 1989; 30: 149.

53 Soong HK. Vinculin in focal cell-to-substrate attachments of spreading corneal epithelial cells. Arch Ophthalmol 1987; 105: 1129-32.

54 Lauweryns B, van den Oord JJ, Volpes R, Foets B, Missotten L. Distribution of very late activation integrins in the human cornea. Invest Ophthalmol Vis Sci 1991; 32: 2079-85.

55 Khodadoust AA, Silverstein AM, Kenyon KR, Dowling JE. Adhesion of regenerating corneal epithelium. Am f Ophthalmol 1968; 65: 339-48.

56 Hirst LW, Kenyon KR, Fogle JA, Hanninen L, Stark WJ. Comparative studies of cornea surface injury in the monkey and rabbit. Arch Ophthalmol 1981; 99: 1066-73.

57 Gipson IK, Grill SM, Spurr SJ, Brennan SJ. Hemidesmosome formation in vitro. F Cell Biol 1983; 97: 849-57.

58 Friedenwald JS. Growth pressure and metaplasia of conjunctival and corneal epithelium. Doc Ophthalmol 1951; 6: 184-92.

59 Haaskjold E, Sandvig KU, Bjerknes R, Kravik K. The early cell kinetic response during healing of corneal epithelial wounds. Ophthalmic Surg 1992;

60 Thoft RA, Friend J, Murphy HS. Ocular surface epithelium and corneal vascularization in rabbits I. The role of wounding. Invest Ophthalmol Vis Sci 1979; 18: 85-92.

61 Shapiro MS, Friend J, Thoft RA. Corneal re-epithelialization from the conjunctiva. Invest Ophthalmol Vis Sci 1981; 21: 135-42.

62 Aitken D, Friend J, Thoft RA. Corneal re-epithelialization from the conjunctiva. Invest Ophthalmol Vis Sci 1988; 29: 224-31.

63 Tseng SCG, Hirst LW, Farazdaghi M, Green WR. Goblet cell density and vascularization during conjunctival transdifferentiation. Invest Ophthalmol Vis Sci 1984; 25: 1168-76.

64 Huang AJW, Watson BD, Hernandez E, Tseng SCG. Induction of conjunctival transdifferentiation on vascularized corneas by photothrombotic occlusion of transdifferentiation on vascularized corneas by photothrom

65 Tseng SCG, Hirst LW, Farazdaghi M, Green WR. Inhibition of conjunctival transdifferentiation by topical retinoids. Invest Ophthalmol Vis Sci 1987; 28: 538-42.

66 Tseng SCG, Farazdaghi M, Rider AA. Conjunctival transdifferentiation induced by systemic vitamin A deficiency in vascularized rabbit corneas. Invest Ophthalmol Vis Sci 1987; 28: 1497-504.

67 Kinoshita S, Friend J, Kiorpes TC, Thoft RA. Keratin-like proteins in corneal and conjunctival epithelium are different. Invest Ophthalmol Vis Sci 1983; 24: 577-81.

68 Harris TM, Berry ER, Pakurar AS, Sheppard LB. Biochemical transformation of bulbar conjunctiva into corneal epithelium: an electrophoretic analysis. Exp Eye Res 1985; 41: 597-605.

69 Thoft RA, Friend J. Biochemical transformation of regenerating ocular surface epithelium. Invest Ophthalmol 1977; 16: 14-20.

70 Kruse FE, Chen JJY, Tsai RJF, Tseng SCG. Conjunctival transdifferentiation is due to incomplete removal of limbal basal epithelium. Invest Ophthalmol is Sci 1990; 31: 1903-13.

71 Dua HS, Forrester JV, Cohen EJ, Laibson PR. Clinical observations on corneal epithelial cell migration in humans. Invest Ophthalmol Vis Sci (suppl) 1993 Ubels JL, Edelhauser HF, Austin KH. Healing of experimental corneal
wounds treated with topically applied retinoids. Am $\mathcal{O}$ Ophthalmol 1983; 95:

73 Perry HD, Hodes LW, Seedor JA, Donnenfeld ED, McNamara TF, 
Golub LM. Effect of doxycycline (Hyclate) on corneal epithelial wound healing in the rabbit alkali-burn model. Cormea 1993; 12: 379-82.

74 Singh G, Foster CS. Epidermal growth factor in alkali-burned corneal epithelial wound healing. Am $\mathcal{F}$ Ophthalmol 1987; 103: 802-7.

75 Sheardown A, Wedge C, Chou L, Apel R, Rootman DS, Cheng Y-L Continuous epidermal growth factor delivery in corneal epithelial wound

76 Kitazawa TK, Kinoshita S, Fujita K, Araki K, Watanabe H, Ohashi Y, et al. The mechanism of accelerated corneal epithelial healing by human epidermal growth factor. Invest Ophthalmol Vis Sci 1990; 31: 1773-8.

77 Wagoner MD, Kenyon KR. Chemical injuries. In: Shingleton BJ, Hersh PS, Kenyon KR, eds. Eye trauma. St Louis: Mosby, 1991: 79-94.

78 Lemp MA, Roddy M. The effect of acetylcysteine (Mucomyst) on reepithelialization of the cornea. Ann Ophthalmol 1974; 6: 893-5.

79 Thorpe GE, Liu GS, Basu PK. Toxic effects of topically administered betagan, betoptic and timoptic on regenerating corneal epithelium. $\mathcal{f}$ Ocular Pharmacol 1988; 4: 359-66.
80 Burstein NL. Corneal cytotoxicity of topically applied drugs, vehicles and preservatives. Surv Ophthalmol 1980; 25: 15-30.

81 Foster CD, Pavan-Langston D. Corneal wound healing and antiviral medication. Arch Ophthalmol 1977; 95: 2062-7.

82 Petroutsos G, Guimaraes R, Giraud J, Pouliquen Y. Antibiotics and corneal epithelial wound healing. Arch Ophthalmol 1983; 101: 1775-8.

83 Stern GA, Schemmer GB, Farber RD, Gorovoy MS. Effect of topical antibiotic solutions on corneal epithelial wound healing. Arch Ophthalmol 1983; 101 644-7.

84 Foster CD, Lass JH, Moran-Wallace K, Giovanoni MS. Ocular toxicity of topical antifungal agents. Arch Ophthalmol 1981; 99: 1081-4.

85 Tripathi BJ, Tripathi RC. Hydrogen peroxide damage to human corneal epithelial cells in vitro. Arch Ophthalmol 1989; 107: 1516-9.

86 Azar DT, Spurr-Michaud J, Tisdale MS, Gipson IK. Altered epithelialbasement membrane interactions in diabetic corneas. Arch Ophthalmol 1992; 110: 537-9. 